close collaboration between radiotherapist and physicist in this field.

The first edition appeared eleven years ago; the new edition has been brought up to date by the inclusion of recent developments and by many useful charts. The book is very valuable as a source of information to the postgraduate and as a guide to the radiotherapist and physicist.

\section{NEW CONCEPTS IN SURGERY OF THE VASCULAR SYSTEM}

By Emile Holman, M.D. Pp. v + 108, with 47 illustrations. Oxford: Blackwell Scientific Publications. 1955. I 8s.

Dr Holman has chosen a good title for his monograph, for it consists of two important lectures, each on a new aspect of a familiar problem. In the first he describes the dramatic changes which have taken place in treating arterial injuries, largely as a result of Korean experience. There the U.S. Army and Marine surgeons reduced the incidence of amputation very dramatically; where 70 per cent. of popliteal artery ligations in the wounds of World War II were followed by amputation in Korea, taking advantage of many favourable circumstances, popliteal artery reconstruction entailed amputation in only 20 per cent. Dr. Holman explains the possibility of reconstructive surgery on technical improvements since I945. It may, however, be that the peculiar conditions of the Korean campaign were as much a factor, for forward surgery was conducted behind a relatively static front, with effective helicopter rescue and evacuation of the moderate numbers of casualties.

In his second lecture Dr. Holman describes his own original work on the dynamics and structural changes in post-stenotic dilatation and in arteriovenous fistulae. He has not only reproduced many of these changes in vitro, so to speak, using physical apparatus only, but also correlates these and similar measurements taken in patients and experimental animals. An interesting hypothesis is produced that fatigue of the kind known to metallurgists also occurs in biological structures. No. direct physical evidence can yet be given but the theory does account for many of the strange phenomena of vascular disease.

A small annoyance to British readers will be the inaccurate account of what must be intended to mean the Farnborough tank tests of the Comet airliner, for, as is well known here, a cyclical stress was applied to the pressure cabin, not a constant unrelenting and high pressure, which indeed would not have been in any sense comparable to the life of this aircraft or indeed to the stress upon an artery either.

In all other respects this is a valuable and important monograph for it throws important new light on the damaged artery, its mode of late failure and its means of early cure. It should be read bs every surgeon.

H.H.G.E.

By G. E. Beaumont, M.A., D.M., F.R.C.P㞐 D.P.H. Pp. xiv +469 , with 74 illustrations London: J. \& A. Churchill Ltd. 1956. 45s. कి

This book consists of a series of case histories $\overrightarrow{0}$ In the first section these are drawn mainly from the author's private practice, and they tell not only off the problems of the patient, but also of the diffte culties that the consultant has to face in his dealing with colleagues and relatives. This provides for. the student a useful introduction to a less familia side of medicine. A second section deals witb cases of tuberculosis and of congestive heart failures Here the emphasis is primarily on the reactions of the patients to their illness. In the final sectio $\vec{B}$ cases are presented by the Socratic method of Question and Answer.

The book sets out to achieve a number of pur= poses. In part it is Dr. Beaumont's personal memoirs, and introduces us to the teacher as wef as to his patients. It emphasises the humanity of patients, and thus forms a valuable counterbalaoce to the reading of standard text-books, and, finaty it also embodies much useful medical informat Most of the latter is at a level best suited to unctero graduate needs; but some (as, for example, the section on spider naevi) will be useful also to posto graduates. The arrangement of the book reallo amounts to providing ward rounds in the librarba and as such it makes enjoyable and instructive reading.

\section{SEXUAL PRECOCITY}

By Hugh Jolly, M.A., M.D., M.R.C.P. Pp. xi⿱⺈ +276 , with 69 illustrations. Oxford: Blackwed Scientific Publications. 1955. 50s.

This book will not disappoint those who we랄 fortunate enough to hear Dr. Jolly present the material for his M.D. thesis to the British Paediatr黑 Association or to the Royal Society of Medicine. N

It includes the case-histories of the 69 children tracked down by the author with such care, as wef as a finely-produced collection of photographs and sections, $a^{+}$very full review of the world literatuge
and both an author and a subject index.

The material is well classified and most clearfy presented, while the discussion of treatment, pa\& ticularly the psychological aspects of management, is sensible and well balanced. Both paediatrician and endocrinologists will find this work invaluablo 